\title{
Remediation of arsenic contaminated soil using soil washing with an acidic and reducing solution
}

\author{
J. G. Kim, J. H. Lee, Y. C. Cho \& S. H. Park \\ Korea Institute of Geoscience and Mineral Resources, Korea
}

\begin{abstract}
Soil contamination with arsenic (As) is a serious environmental concern due to its highly toxicity and carcinogenic property. Iron oxides are known to be the most important factor for controlling As concentration in soil pore water. They adsorb large amount of As and coprecipitate with As. We tried to develop a new washing method of As contaminated soil by the dissolution of iron oxide and desorption of As employing $\mathrm{pH}$ and redox potential adjustment. An As contaminated soil sample was collected at a rice paddy field near a copper smelter, Korea. The As concentration of the soil sample was determined with an aqua-regia extraction method. Washing solutions were prepared to be $0.001-$ $0.1 \mathrm{~N} \mathrm{HCl}$ and $0-3 \% \mathrm{Na}$-dithionite. The soil and washing solution were mixed at 1:4 ratio and the mixtures were reacted for 15,30, 45 and 60 minutes. After the reaction, the soil and washing solution were separated with a centrifugation. The $\mathrm{pH}$, Eh and concentrations of $\mathrm{As}, \mathrm{Fe}$ and $\mathrm{Mn}$ of the washing solution were determined and the As concentration of the washed soil sample was also determined. The separated washing solution was treated with $\mathrm{H}_{2} \mathrm{O}_{2}, \mathrm{CaCl}_{2} \cdot 2 \mathrm{H}_{2} \mathrm{O}$ and cationic organic polymer to remove As. The soil washing with the $0.01 \mathrm{~N}$ $\mathrm{HCl} 3 \% \mathrm{Na}$-dithionite solution for 30 minutes was the most effective in the As removal from the soil reducing As concentration from $43 \mathrm{mg} / \mathrm{kg}$ to $18 \mathrm{mg} / \mathrm{kg}$. The As concentration of the washing solution was reduce from $19.2 \mathrm{mg} / \mathrm{L}$ to $0.76 \mathrm{mg} / \mathrm{L}$ after the waste water treatment.
\end{abstract}

Keywords: soil washing, arsenic, $p H$, Eh. 


\section{Introduction}

The solubility, mobility and toxicity of As in soils are depending on its oxidation state [1]. Arsenite $\left(\mathrm{As}^{3+}\right)$ and arsenate $\left(\mathrm{As}^{5+}\right)$ are the most common species of arsenic under surface environment [2]. The concentration of As in soil porewater is mainly governed by adsorption and precipitation. The adsorption is controlled by iron oxide and aluminum oxide in acidic soil and by carbonate in calcareous soil [3]. Iron (Fe)-, manganese ( $\mathrm{Mn}$ ) and calcium (Ca)-arsenic minerals are the most common As bearing mineral in oxidizing soil and As sulfides are the most common mineral in reducing soil. We developed a soil washing method for the As contaminated soil using the dissolution of As adsorbents and As containing minerals with the $\mathrm{pH}$ and Eh adjustment of washing solution.

\section{Material and method}

Arsenic contaminated soil was collected from a paddy field near a copper smelter operated for 50 years. The collected soil was air-dried and gently ground with a rubber stopper to pass $2 \mathrm{~mm}$ sieve. The texture, mineralogy, ignition loss, $\mathrm{pH}$, electrical conductivity, contents of water soluble cation and anion, and contents of Fe and Mn oxide of the soil sample were determined. The As content of the soil was determined with an aqua-regia extraction method and the As was fractionated into water soluble, Al-oxide, Fe-oxide, reducible, oxidizable and residual forms. The soil washing solution containing $0.001-0.1 \mathrm{~N} \mathrm{HCl}$ and $0-3 \%$ Na-dithionite and the soil reacted at 1soil and 4washing solution for 15-60 minutes. After the reaction and the separation of soil and washing solution, the contents of As in the soil and the washing solution were determined. The separated solution was treated to remove As and $\mathrm{SO}_{4}{ }^{2-}$ with $\mathrm{H}_{2} \mathrm{O}_{2}, \mathrm{CaCl}_{2} \cdot 2 \mathrm{H}_{2} \mathrm{O}$ and cationic polymer. After the treatment, the concentrations of $\mathrm{As}$ and $\mathrm{SO}_{4}{ }^{2-}$ of the washing solution were determined.

\section{Results and discussion}

The physical, mineralogical and chemical properties of the soil are shown in table 1 .

Table 1: Physical, mineralogical and chemical properties of the soil. Q: quartz, F: feldspar, C: chlorite, M: mica, K: kaolinite.

\begin{tabular}{|c|c|c|c|c|c|c|c|c|c|c|c|c|}
\hline Texture & Min. & $\mathrm{pH}$ & EC & I.L. & \multicolumn{4}{|c|}{ Water soluble cation } & \multicolumn{2}{|c|}{ Water soluble anion } & \multicolumn{2}{|c|}{ DCB extrac. } \\
\hline \multirow{3}{*}{$\begin{array}{l}\text { Silt } \\
\text { loam }\end{array}$} & \multirow{3}{*}{$\begin{array}{c}\mathrm{Q}, \mathrm{F}, \\
\mathrm{C}, \mathrm{M}, \\
\mathrm{K}\end{array}$} & \multirow{3}{*}{6.13} & \multirow{3}{*}{$\begin{array}{c}0.78 \\
(\mathrm{mS} / \mathrm{cm})\end{array}$} & \multirow{3}{*}{$\begin{array}{l}5.7 \\
(\%)\end{array}$} & $\mathrm{Ca}$ & $\mathrm{Mg}$ & $\mathrm{Na}$ & $\mathrm{K}$ & $\mathrm{Cl}$ & $\mathrm{SO} 4$ & $\mathrm{Fe}$ & $\mathrm{Mn}$ \\
\hline & & & & & \multicolumn{8}{|c|}{ - } \\
\hline & & & & & 116 & 64.6 & 499 & 61.9 & 187.5 & 169.2 & 2351 & 281.1 \\
\hline
\end{tabular}

The As content of the soil determined with the aqua-regia extraction method was $43.0 \mathrm{mg} \mathrm{kg}^{-1}$ and Fe-oxide, reducible and residual forms were the dominant As fractions (table 2). 
Table 2: $\quad$ As fractions in the soil.

\begin{tabular}{|c|c|c|c|c|c|}
\hline $\begin{array}{c}\text { Water } \\
\text { soluble }\end{array}$ & Al-oxide & Fe-oxide fo & Reducible & Oxidizable & Residual \\
\hline \multicolumn{6}{|c|}{ 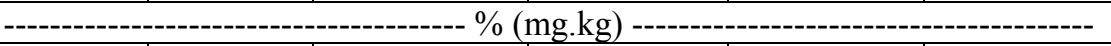 } \\
\hline $2(0.78)$ & $\begin{array}{c}11.4 \\
(4.51)\end{array}$ & $34.5(13.69)$ & $23.5(9.30)$ & $2.4(1.10)$ & $26.2(10.30)$ \\
\hline
\end{tabular}

Amount of extracted As during the soil washing increased with decreasing Eh (fig. 1) and increasing amount of extracted Fe (fig. 2).

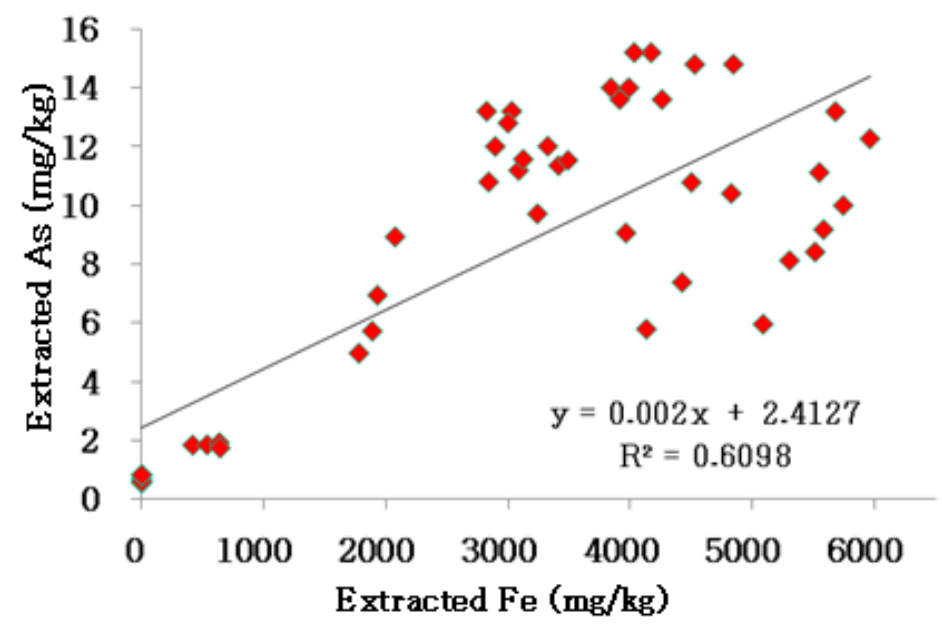

Figure 1: $\quad$ Relationship between amount of extracted As and Fe.

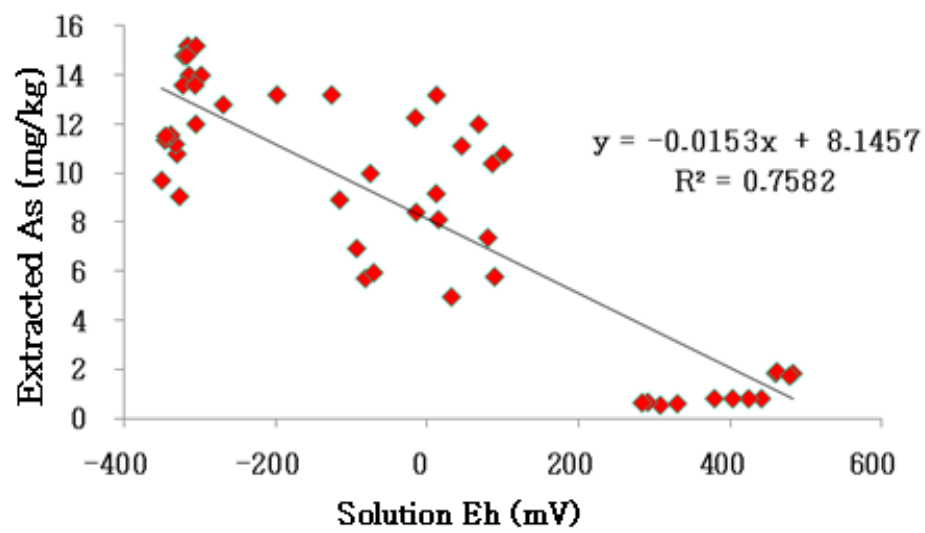

Figure 2: Relationship of washing solution Eh and amount of extracted As. 
The optimum condition for As extraction from the soil was $0.01 \mathrm{~N} \mathrm{HCl} 33 \%$ Na-dithionite washing solution and 30 minutes of reaction. The As concentration of the soil was reduced from $43.0 \mathrm{mg} \mathrm{kg}^{-1}$ to $18.3 \mathrm{mg} \mathrm{kg}^{-1}$ after the soil washing with the optimum condition. The As concentration of the washing solution reduced from $5.0 \mathrm{mg} \mathrm{l}^{-1}$ to $0.7 \mathrm{mg} \mathrm{l}_{-1}$ and $\mathrm{SO}_{4}{ }^{2-}$ concentration from 10,400 $\mathrm{mg} \mathrm{l}^{-1}$ to $2,440 \mathrm{mg} \mathrm{l}^{-1}$ with waste water treatment. The XRD and SEM data of the precipitate after the waste water treatment confirmed the presence of Fe-oxide and gypsum. The soil characteristics and chemical properties of the waste water indicate that As was extracted from the soil by dissolution of Fe-oxide with decreasing $\mathrm{Eh}$ and $\mathrm{pH}$. The removal of $\mathrm{As}$ and $\mathrm{SO}_{4}{ }^{2-}$ from waste water was due to the precipitation of Fe-oxide and gypsum by the treatment.

\section{Conclusion}

Extraction As from the soil during soil washing was mainly due to the increased solubility of Fe-oxide with the reduction of $\mathrm{pH}$ and Eh. The removal of As and $\mathrm{SO}_{4}{ }^{2-}$ from the waste water was mainly due to formation of Fe-oxide and gypsum during the waste water treatment.

\section{References}

[1] Masscheleyn, P.H., Delaune, R.D. \& Patrick, W.H., Effect of redox potential and $\mathrm{pH}$ on arsenic speciation and solubility in a contaminated soil. Environ. Sci. Technol., 25, pp. 1414-1419. 1991.

[2] Cullen, W.R. \& Reimer, K.J., Arsenic speciation in the environment. Chem. Rev., 89, pp. 719-764, 1989.

[3] Muhammad, S., Arsenic chemistry in soils: a review of thermodynamic predictions and field observations. Water, Air, and Soil Contamination, 93, pp. 117-136. 1997. 